\title{
Two different endotracheal tube manufacturing defects
}

\author{
Ayse Belin Ozer, Omer Lutfi Erhan
}

\begin{abstract}
Introduction: Although manufacturing defects related to airway equipment are not so common in practice, it risks the safety of the airway. Prompt recognition of equipment malfunction can prevent life threatening complications. Case Series: Case 1: A 25-year-old patient had anesthesia induction for septorhinoplasty surgery. After the patient was ventilated via mask and intubated without problem, peak and plateau pressures increased above $35 \mathrm{Cm} \mathrm{H}_{2} \mathrm{O}$ on controlled ventilation. It was noticed that the anesthetic reservoir bag did not maintain adequate compliance in a setting of high peak and plateau pressure and was thought to be due to a faulty endotracheat tube (ETT) connecter. We noticed that lumen of ET tube connector was narrow and connecter has been changed. After this change the relaxation of the balloon and a decrease in the ventilator pressures were noted. Case 2: A 45-year-old female patient had anesthesia induction for hysterectomy. After induction it was noted that there was a leak in the circuit, which was traced to the connection between the ETT and the inflation tube. An opening at the point of the connection of the EET with the inflation tube was detected. ETT
\end{abstract}

Ayse Belin Ozer ${ }^{1}$, Omer Lutfi Erhan ${ }^{2}$

Affiliations: ${ }^{1} \mathrm{MD}$, Assistant Professor, Department of Anaesthesiology and Reanimation, Faculty of Medicine, Firat University, Elazig, Turkey; ${ }^{2} \mathrm{MD}$, Professor, Department of Anaesthesiology and Reanimation, Faculty of Medicine, Fırat University, Elazig, Turkey.

Corresponding Author: Ayse Belin Ozer, Firat University Faculty of Medicine, Anaesthesiology and Reanimation Department, 23119, Elazig, Turkey; Ph: +90-4242333555/2069; Fax: +90-424-2388096; Email: abelinozer@gmail.com

Received: 21 January 2012

Accepted: 16 October 2012

Published: 01 March 2013 was changed and anesthesia was maintained with no further problems. Conclusion: Difficult ventilation after successful endotracheal intubation can be due to equipment failure such as faulty ETT connecter and faulty inflation tube.

Keywords: Endotracheal tube, Manufacturing defect, Leakage, Increased pressure

$$
* * * * * * * * *
$$

Ozer AB, Erhan OL. Two different endotracheal tubemanufacturing defects. International Journal of Case Reports and Images 2013;4(3):150-153.

$$
* * * * * * * * *
$$

doi:10.5348/ijcri-2013-03-282-CS-3

\section{INTRODUCTION}

Endotracheal (ET) tubes are used for facilitating ventilation during various surgical procedures performed under general anesthesia. It is a known fact that there can be manufacturing defects of ET tubes used during anesthesia application [1-3]. Equipment should be checked for defects prior to anesthetic induction. If not recognized, they can cause lifethreatening problems during anesthesia application. We present two cases to remind of ET tubes' manufacturing defects which adversely affected ventilation.

\section{CASE SERIES}

Case 1: A 25-year-old patient for planned septorhinoplasty was evaluated as American Society of Anesthesiologists grade I on preoperative examination. The patient was taken to the operating theater and vascular access was obtained. His heart rate, peripheral 
oxygen saturation and blood pressure were monitored non-invasively. Anesthesia was induced with routine doses of propofol, vecuronium and fentanyl and the patient was ventilated via mask without problem. $\mathrm{He}$ was intubated with an ET tube with transparent and spirals (size II/7,5 mm). After it was observed that both lungs were equally ventilated, the ET tube cuff was inflated and ventilation was changed to control mode from manual mode. As peak and plateau pressures increased above $35 \mathrm{~cm} \quad \mathrm{H}_{2} \mathrm{O}$ during controlled ventilation, the ventilation was changed back to manual mode. The lungs were auscultated again and normal lung sounds were heard. It was detected that the breathing bag did not inflate well during expiration along with inspiratory difficulty. The anesthesia devices were checked by detaching the ET tube from the anesthesia machine, and no problem was detected. Simultaneously, the patient was ventilated via an ambubag. Upon inspecting the ET tube, it was noticed that the lumen of ET tube connector was narrow and connecter was immediately changed (Figure 1). As soon as it was changed, the relaxation of the breathing bag and a decrease in the peak and plato pressures were noted. Difficulty with insertion of sylet was incidentally noted prior to intubation. In this process, there wasn't decrease in the patient's $\mathrm{SpO} 2$ level, its level continued to be $98-99 \%$.

Case 2: A 45-year-old female patient in ASA II with a planned hysterectomy had anesthesia induction by routine doses of propofol, vecuronium and fentanyl for her surgery. She was intubated with a transparent ET tube of $7.5 \mathrm{~mm}$ (size 30/7,5). On hearing the leaking air after the patient was intubated and the cuff was inflated, the system and ET tube was checked. No problems in the system were detected. Localization of air leak was found by palpating and by listening to leakage flow. A hole at the point of the connection of the ET tube with

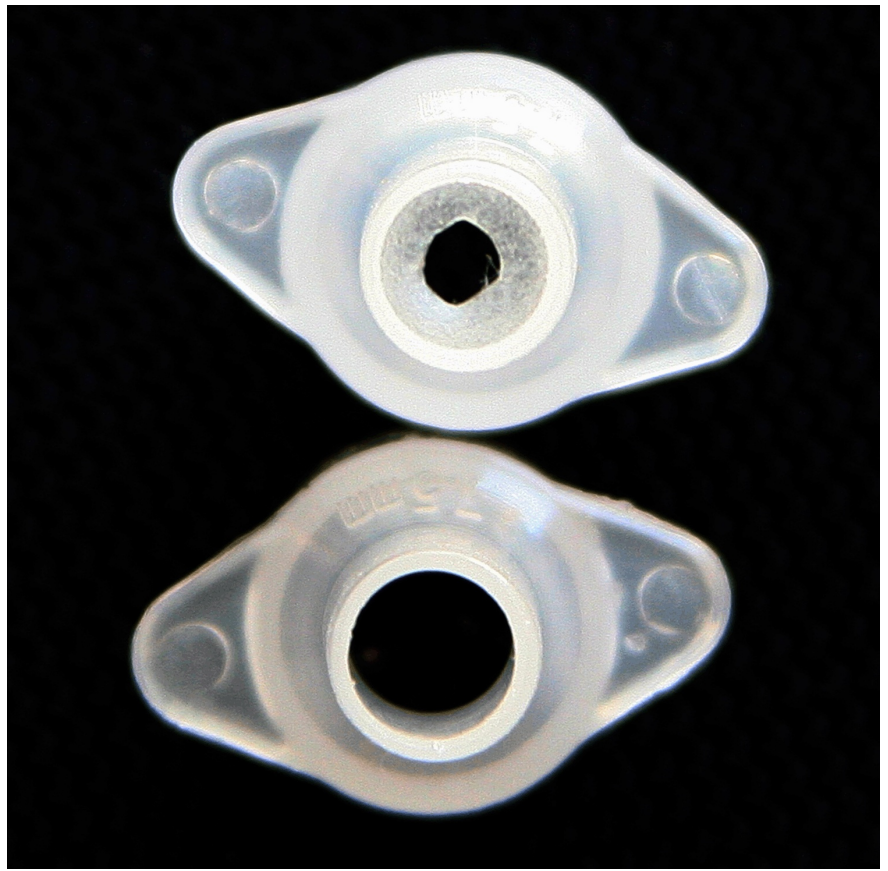

Figure 1: Narrow orifice of tube connector (above) as compared to other tube of same size (below). the inflation tube was detected (Figure 2). ETT was changed and anesthesia was maintained with no further problems. In this process, there was no decrease in the patient's $\mathrm{SpO} 2$ level.

\section{DISCUSSION}

Improperly checking anesthesia equipment and instruments prior to use can lead to patient injury. It is also associated with an increased risk of severe postoperative morbidity and mortality. Therefore, in 2008, American Society of Anethesiologists (ASA) recommendations for equipment checkout are recommends by Sub-Committee of ASA Committee on Equipment and Facilities. According to this guide, the following steps should be verified on a daily basis: 1) auxiliary oxygen cylinder and self-inflating manual ventilation device are available and functioning, 2) patient suction is adequate to clear the airway, 3) turn on anesthesia delivery system and confirm that $\mathrm{AC}$

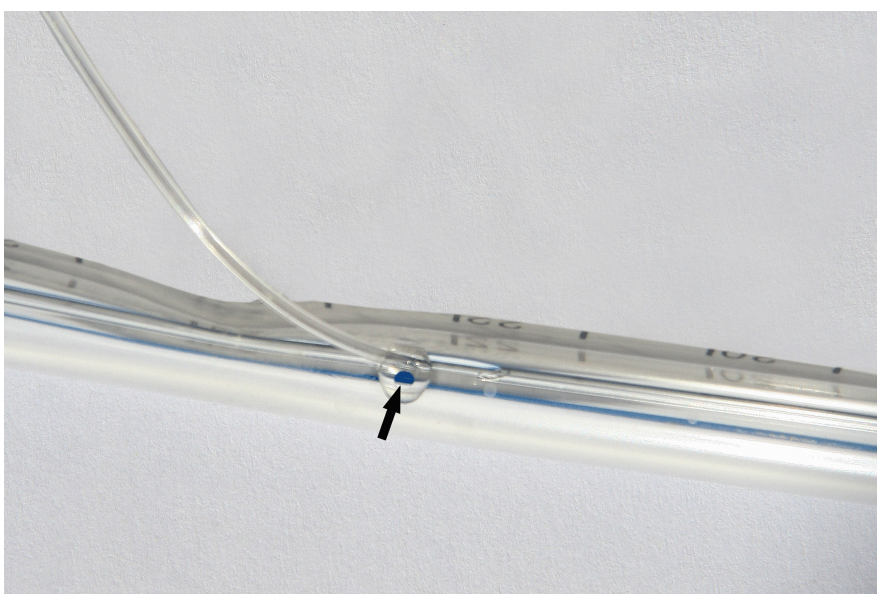

Figure 2: An opening at the point of the connection of the EET with the inflation tube.

power is available, 4) availability of required monitors and check alarms, 5) pressure is adequate on the spare oxygen cylinder mounted on the anesthesia machine, 6) piped gas pressures are $\geq 50$ psig, 7) vaporizers are adequately filled and, if applicable, that the filler ports are tightly closed, 8) there are no leaks in the gas supply lines between the flowmeters and the common gas outlet, 9) test scavenging system is function, 10) caliberate the oxygen monitor and check the low oxygen alarm, 11) carbon dioxide absorbent is not exhausted, 12) breathing system pressure and leak testing, 13) gas flows properly through the breathing circuit during both inspiration and exhalation, 14) document completion of checkout procedures, and 15) confirm ventilator settings and evaluate readiness to deliver anesthesia care. Step $2,4,7,11,12,13,14$ and 15 should be done prior to each procedure. In our department, anesthesia equipment are prepared in accordance with ASA recommendation [4]. 
For a safe airway and ventilation, not only anesthesia machine and equipment, but also the equipment used to provide the airway should be checked. There have been case reports of various equipmental failures with respect to face masks and double lumen endotracheal tubes $[1$, 2, 5]. Endotracheal tube manufacturing defects are usually noticed during the preoperative preparation period. In preoperative preparation period, ET tube, particulary its cuff and lumen, should be checked. If manufacturing defect is not noticed in preoperative period, it can result in serious airway obstructions $[1,3$, 6-9] or air leakage during anesthesia [10-12]. If manufacturing defect of ET tube is suspected, then the equipment must be immediately changed.

An airway obstruction should be kept in mind if the airway and breathing bag pressures are increasing or if there is ventilation difficulty before enough tidal volume is reached. When this happens one should switch to manual mode from controlled mode and the anesthesia system should be checked. If there is no problem in the system, the ET tube should be checked. Herniation of the ET cuff, kinking of the tube, intraluminal plastic film or obstruction by meniscus and obliteration of the ETT connector are the known manufacturing defects that can result in difficulty in ventilation $[1,3,6-9]$. In case 1 , there was a narrowing of the tube connector making ventilation difficult. There was a reported difficulty in inserting the stylet inside the tube which makes us think that this may have happened due to narrow lumen itself or total or near total occlusion or narrowing of the tube which may have been dilated by inserting the stylet.

Some manufacturing defects may cause air leakage and it may cause adverse effects on the ventilation [10-12]. When this happens, one can hear the leakage sound, the tidal volume is not enough and balloon and airway pressures decrease. Two cases reported in the literature were similar to our second case where they reported air leakage from the point of connection of inflation tube and air leakage due to an asymmetric cuff $[10-12]$.

\section{CONCLUSION}

Although manufacturing defects are not so common, they risk the safety of airway. Therefore, it is important to check anesthesia equipment against a possible manufacturing defect as well as anesthesia machine in preoperative period. When ventilation problems happen after a successful intubation, ventilator, anesthesia instruments (ETT, mask, LMA), devices and lungs should be checked. Problem should be identified with a systematic approach and fixed. Prompt recognition of equipmental malfunction can prevent life-threatening complications.

$* * * * * * * * *$

\section{Editor's Note}

Name of the manufacturing companies and LOT number has not been rewarded in the article.

\section{Author Contributions}

Ayse Belin Ozer - Substantial contributions to conception and design, Acquisition of data, Drafting the article, Revising it critically for important intellectual content; Final approval of the version to be published Omer Lutfi Erhan - Substantial contributions to conception and design, Acquisition of data, Drafting the article, Revising it critically for important intellectual content, Final approval of the version to be published

\section{Guarantor}

The corresponding author is the guarantor of submission.

\section{Conflict of Interest}

Authors declare no conflict of interest.

\section{Copyright}

(C) Ayse Belin Ozer et al. 2013; This article is distributed under the terms of Creative Commons attribution 3.0 License which permits unrestricted use, distribution and reproduction in any means provided the original authors and original publisher are properly credited. (Please see www.ijcasereportsandimages.com/copyright-policy.php for more information.)

\section{REFERENCES}

1. Chen HS, Jawan B, Tseng CC, Cheng KW, Wang CH. Difficult Ventilation with a Double-Lumen Endotracheal Tube: An Unusual Manufacturing Defect. Anesth Analg 2005;101(4):1094-7.

2. Yasar MA, Erhan OL, Bestas A, Avci L, Ezici M. An anaesthesia face mask with no lumen. Eur J Anaesth 2005;22(7):561-2.

3. Hajimohammadi F, Taheri A, Eghtesadi-Araghi P. Obstruction of Endotracheal Tube; A Manufacturing Error. Middle East J Anesthesiol 2009;20(2):303-5.

4. https://www.asahq.org/For-Members/ClinicalInformation/2008-ASA-Recommendations-forPreAnesthesia-Checkout.aspx. American Society of Anesthesiologists.

5. Das Adhikary S, Krishnan BS. Unusual Defect in a Double-Lumen Endotracheal Tube. Anesth Analg 2006;103(6):1594-5.

6. Sofi K, El-Gammal K. Endotracheal tube defects: hidden causes of airway obstruction. Saudi J Anaesth 2010;4(2):108-10.

7. Chua WL, Ng AS. A defective endotracheal tube. Singapore Med J 2002;43(9):476-8.

8. Shamshery C, Kannaujla AK, Gautam S. Ventilation failure due to endotracheal tube T-connector defect. Indian journal of Anaesthesia 2010;54(4):357-8.

9. Bharti N, Bala I, Sharma K. Endotracheal tube connector defect as a cause of high airway pressure. Paediatr Anaesth 2012;22(5):502-3.

10. Lewer BM, Karim Z, Henderson RS. Large air leak from an endotrachea tube due to a manufacturing defect. Anesth Analg 1997;85(4):944-5.

11. Rho EH, Long TR, Wass CT. Inadequate Tidal Volume: Asymmetric Endotracheal Tube Cuff Inflation Resulting in a Massive Persistent Airway Leak. Anesth Analg 2003;97(6):1853. 
12. Kapoor D, Singh A. An unusual site of an occult air leak in an armoured endotracheal tube in the midst of surgery. Indian J Anaesth 2012;56(1):99-100.

Access full text article on other devices

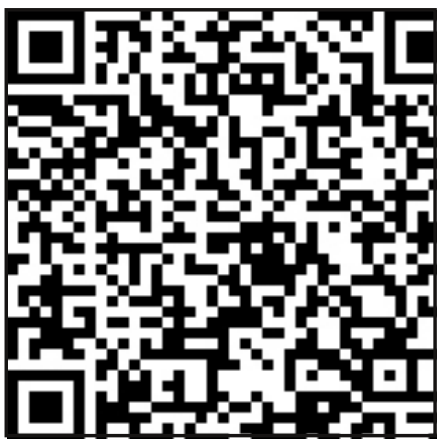

Access PDF of article on other devices

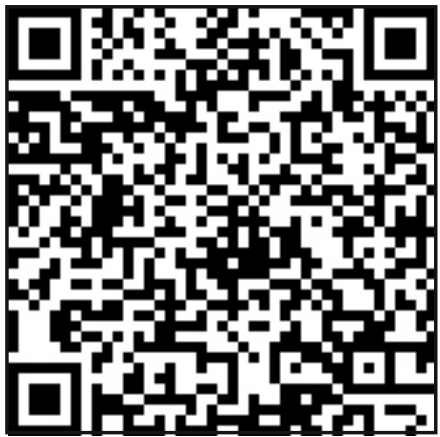

